\title{
Isolation, Identification, and Bioaugmentation of an Oxytetracycline-Degrading Bacterium Staphylococcus sp. TJ-1 in Composting of Swine Manure
}

\author{
Kun Zhang ${ }^{1}$, Mengting Guo ${ }^{1}$, Xin Zheng ${ }^{1}$, \\ Dongsheng Shen ${ }^{1,2}$, Jiali Shentu ${ }^{1,2}$, Meizhen Wang ${ }^{1,2}$ \\ ${ }^{1}$ College of Environmental Science and Engineering, \\ Zhejiang Gongshang University, \\ Hangzhou, China \\ ${ }^{2}$ Zhejiang Provincial Key Laboratory of Solid Waste Treatment and Recycling, \\ Hangzhou, China
}

\begin{abstract}
To enable hazard-free treatment of swine manure, a bacterium capable of using oxytetracycline as the sole source of carbon (Staphylococcus sp. TJ-1) was isolated. The organism was able to degrade $80.7 \%$ of oxytetracycline in 5.5 d when cultured at $\mathrm{pH} 7.0,30^{\circ} \mathrm{C}$ and $100 \mathrm{mg} / \mathrm{L}$ of oxytetracycline. For its application in engineering, the key conditions for composting were optimized using the custom design. When setting the conditions as $70 \%$ of the initial percentage of moisture, an initial $\mathrm{C} / \mathrm{N}$ of 30 , inoculation with $1 \% \mathrm{TJ}-1$ and the stack-turning every $1.5 \mathrm{~d}$, the degradation of oxytetracycline reached $98.2 \%$, indicating that the organism could be used for agriculture application to reduce the oxytetracycline pollution.
\end{abstract}

Keywords-oxytetracycline degradation; compost of swine manure; bioaugmentation; Staphylococcus sp. TJ-1

\section{INTRODUCTION}

Veterinary antibiotics (Vas) are widely used in many countries to treat disease, protect the health, and promote the growth of animals. In China, approximately 6000 tons of Vas is used per year [1]. According to Yang et al., 50$90 \%$ of the feeding-antibiotics could not be absorbed by the gut of the animal, and the output of antibiotics in manure by livestock and poultry is reportedly 2170 tons per year [2]. After their output, they enter into soil, ground water, river sediment and so on. If these antibiotics could not be efficiently degraded, they possible increased in antibiotic resistant genes in the environment, which will lead to serious environmental problems including ecological risk and human health damage [3, 4]. Thus, it could be paid more attention to the Vas degradation in environment.

There are many technologies that reduce or degrade Vas in manure, including aerobic composting and anaerobic composting. Composting is an effective method of reducing Vas in animal manure that has the advantages of low cost, reduced secondary pollution and the ability to treat large amounts of Vas [5].

Oxytetracycline is one of the most commonly used Vas in agriculture. Zhang et al. reported that residual oxytetracycline could be more than $100 \mathrm{mg} / \mathrm{kg}$ in manure, which bring significant effect on environment [6]. Moreover, the stability of oxytetracycline was significantly higher than that of other Vas. Its half-life in composting could be up to $30 \mathrm{~d}$, and it could still be detected after five months $[7,8]$. Thus, in order to reducing the hazardous effect of oxytetracycline on environment, some strategies should be adopted to accelerate oxytretracycline degradation in composting.

Bioaugmentation using specialized bacteria has proven effective in improving the efficiency of bioremediation by rapidly reducing recalcitrant compounds [6]. Therefore, the first aim of present work was to isolate, identify and characterize a bacterium with a high capacity for degradation of oxytetracycline. The conditions for bioaugmentation with the oxytetracyclinedegrading bacterium for swine manure treatment was then determined as a further aim. Overall, the results presented here are beneficial for the hazard-free treatment of swine manure, which is the cause of many serious ecological problems.

\section{MATERIALS AND METHODS}

\section{A. Media}

Inorganic salt medium of oxytetracycline (ISM) (g/l) was composed of $\left(\mathrm{NH}_{4}\right)_{2} \mathrm{SO}_{4}(2.0), \mathrm{K}_{2} \mathrm{HPO}_{4}(0.5)$ and $\mathrm{NaH}_{2} \mathrm{PO}_{4}$ (0.5) adjusted to $\mathrm{pH}$ 7.0. The medium was autoclaved for $30 \mathrm{~min}$ at $121^{\circ} \mathrm{C}$ and allowed to cool to $55^{\circ} \mathrm{C}$, at which time filtrate-sterilized oxytetracycline was added. LB culture medium $(\mathrm{g} / \mathrm{l})$ was composed of beef extract (5.0) and peptone (10.0), and $\mathrm{NaCl}$ (10.0) adjusted to $\mathrm{pH}$ 7.0. Solid medium contained $20 \mathrm{~g}$ agar per liter.

\section{B. Isolation of oxytetracycline-degrading bacterium}

A sample of swine manure was obtained from Changxing Huzhou Zhejiang Province. Enrichment of the oxytetracycline-degrading bacteria from the swine manure was conducted by transferring $1 \mathrm{~g}$ of swine manure to a $300-\mathrm{ml}$ flask containing $100 \mathrm{ml}$ ISM with $100 \mathrm{mg} / \mathrm{l}$ oxytetracycline and incubating the mixture on a reciprocal shaker at $30^{\circ} \mathrm{C}$ and $140 \mathrm{r} / \mathrm{min}$ for $7 \mathrm{~d}$. Next, $1 \mathrm{ml}$ of the swine manure culture was transferred to fresh oxytetracycline-ISM. After 1 month of enrichment, the culture was serially diluted and spread onto oxytetracycline-ISM agar plates containing $100 \mathrm{mg} / \mathrm{l}$ oxytetracycline. Following incubation at $30^{\circ} \mathrm{C}$ for $48 \mathrm{~h}$, 
individual colonies were selected and streaked onto new agar plates repeatedly until a bacterium capable of using oxytetracycline as the sole source of carbon was isolated.

\section{Identification of strain TJ-1}

The genomic DNA was extracted using a Bacterium Genomic DNA Extract Kit (Bioteke, China), after which the 16S rDNA was amplified by polymerase chain reaction (PCR) using the method described by song et al. [9].

The obtained 16S rDNA sequence was aligned in GenBank using the BLAST program, then subjected to multiple sequence analysis using Clustal X (Version 1.8). Phylogenetic and distance analysis of the aligned sequences was then performed using Molecular Evolutionary Genetics Analysis (MEGA, Version 5.05). Finally, the maximum parsimony method was used to develop a phylogenetic tree, which was evaluated by bootstrap analysis based on 1,000 resamplings.

\section{Bacterial growth and oxytetracycline degradation by strain TJ-1}

The dynamic curve of the isolate was developed as follows: $3 \%$ pre-cultured bacteria $\left(\mathrm{OD}_{600}=1.251\right)$ was inoculated into $500 \mathrm{ml}$ flasks with $150 \mathrm{ml}$ of ISM containing $100 \mathrm{mg} / \mathrm{l}$ oxytetracycline at a $\mathrm{pH}$ of 7.0 and then cultured on a reciprocal shaker at $30^{\circ} \mathrm{C}$ and $130 \mathrm{rpm}$. The culture was then sampled to measure the cell growth and oxytetracycline degradation.

To determine the optimum $\mathrm{pH}$ for $\mathrm{TJ}-1$ cell growth and its degradation of oxytetracycline, the initial $\mathrm{pH}$ of the ISM was adjusted to 4.0, 5.0, 6.0, 7.0, 8.0, 9.0 and.10.0, after which $3 \%$ pre-cultured bacteria $\left(\mathrm{OD}_{600}=1.387\right)$ was inoculated into ISM containing $100 \mathrm{mg} / \mathrm{l}$ oxytetracycline. To evaluate the dependence of cell growth and oxytetracycline degradation on culture temperature, 3\% pre-cultured bacteria $\left(\mathrm{OD}_{600}=0.807\right)$ was inoculated into ISM containing $100 \mathrm{mg} / \mathrm{l}$ oxytetracycline and then cultured at $4^{\circ} \mathrm{C}, 25^{\circ} \mathrm{C}, 30^{\circ} \mathrm{C}, 35^{\circ} \mathrm{C}, 40^{\circ} \mathrm{C}, 45^{\circ} \mathrm{C}$ and $55^{\circ} \mathrm{C}$. In general, the bacterial strain cannot grow at $4^{\circ} \mathrm{C}$. However in order to make sure of it, we set this temperature so we could store the samples. Every treatment has three replicates. Except the optimization of temperature, all cultures were incubated on a reciprocal shaker at $30^{\circ} \mathrm{C}$ and $130 \mathrm{rpm}$. Finally, all cultures were sampled at $96 \mathrm{~h}$ for cell growth and oxytetracycline degradation.

\section{E. Bioaugmentation with strain TJ-1 in composting of swine manure}

Strain TJ-1 was inoculated in the composting system with aim to accelerate the oxytetracycline degradation in swine manure. The swine manure for this study was collected from Huajiachi, Hangzhou, Zhejiang, China. The fresh swine manure was tested without oxytetracycline, which was tested by high performance liquid chromatography (HPLC) as mentioned in Section 2.6. In addition, sawdust used to adjust $\mathrm{C} / \mathrm{N}$ ratio, was purchased from a timber mill in the suburbs of Hangzhou.
The basic properties of both materials are shown in Table I.

TABle I. BAsic PROPERTIEs of RAW MAterials.

\begin{tabular}{|l|l|l|l|l|}
\hline \multicolumn{1}{|c|}{ Material } & Moisture\% & $\begin{array}{c}\text { C\% (in dry } \\
\text { weight) }\end{array}$ & $\begin{array}{c}\text { N\% (in dry } \\
\text { weight) }\end{array}$ & C/N \\
\hline $\begin{array}{l}\text { Swine } \\
\text { Manure }\end{array}$ & 69.8 & 39.4 & 1.8 & 21.9 \\
\hline Sawdust & 8.5 & 49.4 & 0.74 & 66.8 \\
\hline
\end{tabular}

TABLE II. LEVELS AND CODES OF VARIABLES SELECTED FOR THE CUSTOM DESIGN.

\begin{tabular}{|l|l|l|l|l|l|}
\hline \multirow{2}{*}{\multicolumn{1}{|c|}{ Variables }} & \multicolumn{2}{c|}{ Symbols $^{\mathrm{a}}$} & \multicolumn{3}{c|}{ Coded Levels } \\
\cline { 2 - 6 } & Uncoded & Coded & -1 & 0 & 1 \\
\hline Moisture (\%) & $\mathrm{X}_{1}$ & $\mathrm{x}_{1}$ & 50 & 60 & 70 \\
\hline C/N & $\mathrm{X}_{2}$ & $\mathrm{X}_{2}$ & 20 & 25 & 30 \\
\hline $\begin{array}{l}\text { Microbial } \\
\text { inoculation (\%) }\end{array}$ & $\mathrm{X}_{3}$ & $\mathrm{X}_{3}$ & 0 & 0.5 & 1 \\
\hline $\begin{array}{l}\text { Stack-turning } \\
\text { (times/d) }\end{array}$ & $\mathrm{X}_{4}$ & $\mathrm{x}_{4}$ & 1 & 2 & 3 \\
\hline
\end{tabular}

${ }^{\mathrm{a}} \mathrm{X}_{i}=\left(\mathrm{X}_{i}-\mathrm{X}_{0}\right) / \delta \mathrm{X}$, where $\mathrm{X}_{0}$ is value of the $\mathrm{X}_{i}$ at the center point and $\delta \mathrm{X}$ presents the step change.

Based on our previous investigations, the \% moisture, $\mathrm{C} / \mathrm{N}$ ratio and stack-turning frequency have the important effects on common compost of swine manure. Thus, in order to good-performance of bioaugmentation of strain TJ-1 into the swine manure compost, the three aforementioned factors and the rate of inoculation were optimized using a custom design. The levels of the variables are given in Table II.

According to the experimental design, the \% moisture and initial $\mathrm{C} / \mathrm{N}$ ratio were adjusted using the sawdust. Prior to composting, $150 \mathrm{mg} / \mathrm{kg}$ of oxytetracycline was added to the $5 \mathrm{~kg}$ swine manure, which was subsequently placed in darkness for $24 \mathrm{~h}$ to equilibrate. Afterward, the mixture was inoculated with strain TJ-1 with an $\mathrm{OD}_{600}$ value of 1.376 according to the designed proportions. The mixture was then composted at $30 \pm 5^{\circ} \mathrm{C}$ in a warm house. All composts were stack-turned for aeration according to the experimental design. All composts were sampled at 0 and $12 \mathrm{~d}$ to monitor oxytetracycline degradation. Every treatment has three replicates. Meanwhile, the compost with initial water rate of $70 \%$, initial concentration of oxytetracycline $150 \mathrm{mg} / \mathrm{L}$, and initial C/N ratio of 30 was taken as black.

\section{F. Analytical methods}

Bacterial growth was measured based on the absorbance at $600 \mathrm{~nm}$ using a Unico UV-2000 spectrophotometer. Oxytetracycline concentration was determined using a Waters high performance liquid chromatography (HPLC) with a Waters e2695 spectrophotometer and a Waters 2489 UV/Visible detector at a detection wavelength of $365 \mathrm{~nm}$ and a temperature of less than $30^{\circ} \mathrm{C}$. The mobile phase, which contained $25 \%$ acetonitrile and $75 \% 0.01 \mathrm{M}$ oxalic acid, was applied to an XBridge ${ }^{\mathrm{TM}} \mathrm{C} 18$ column $(5.0 \mu \mathrm{m}$ and 4.6 
$\mathrm{mm} \times 250 \mathrm{~mm}$ ) at a flow rate $1.000 \mathrm{ml} / \mathrm{min}$. The sample injection volume was 20 ul.

\section{G. Statistical analysis}

All data are expressed as the mean \pm standard error (SE). Statistical analyses were performed using one-way ANOVA conducted with SPSS (version 16.0) and surface regression (JMP 7.0.1, SAS Institute Inc., Cary, North Carolina, USA) based on fitting to a second-order polynomial model. Differences were considered significant at $p<0.05$.

\section{RESULTS AND DISCUSSIONS}

\section{A. Isolation and identification of oxytetracycline- degrading bacterium}

A bacterium using oxytetracycline as the sole source of carbon was isolated from swine compost samples and denoted TJ-1. On the plates containing oxytetracycline, strain TJ-1 formed yellow round colonies with smooth surfaces. Microscopic observation revealed that strain TJ1 was a Gram-positive, round and non-flagellum bacterium.

The 16S rDNA sequence was amplified from the total DNA of TJ-1 by PCR, after which its sequence was determined and deposited in the GenBank database under accession number JN794602. BLAST searches of the NCBI website were subsequently used for analysis of the 16S rDNA gene and MEGA 5.05 was used to construct a phylogenetic tree. As shown in Figure 1, the 16S rDNA sequence of strain $\mathrm{TJ}-1$ had $97 \%$ similarity to that of Staphylococcus sp. R-25657; accordingly, strain TJ-1 was classified as Staphylococcus sp.

\section{B. Bacterial growth and oxytetracycline degradation by strain TJ-1}

In preliminary study, $100 \mathrm{mg} / \mathrm{l}$ oxytetracycline ISM without inoculation was cultured in $30^{\circ} \mathrm{C}$ and $130 \mathrm{rpm}$ to estimate its natural lose. After $72 \mathrm{~h}$, there was 97.7-99.5 $\mathrm{mg} / \mathrm{l}$ oxytetracycline in ISM detected. Thus, its natural lose was limited. All in following study we think the loss of oxytetracycline was mainly degraded by bacteria.

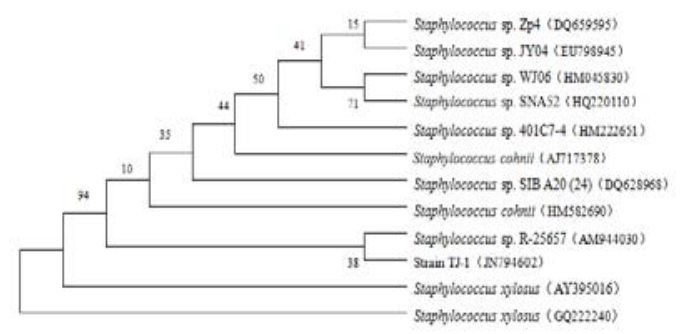

Figure 1. Phylogenetic tree of Staphylococcus sp. TJ-1 based on its 16S rDNA sequence.

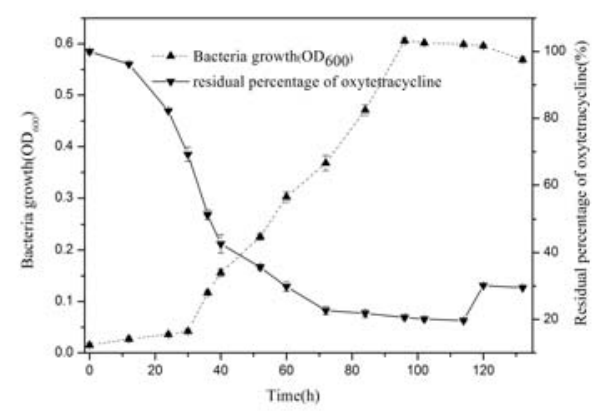

Figure 2. Cell growth and oxytetracycline degradation curves.

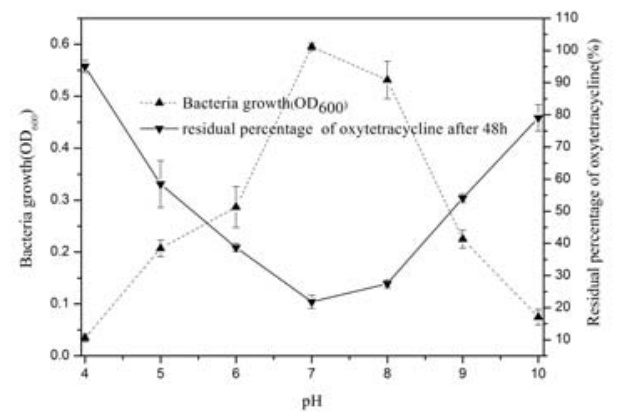

Figure 3. Effect of initial $\mathrm{pH}$ on cell growth and oxytetracycline degradation.

Dynamic curves of growth and oxytetracycline degradation by strain TJ-1 are shown in Figure 2. There was a $30 \mathrm{~h}$ lag phase in growth and oxytetracycline degradation by strain TJ-1, after which the bacterium entered the logarithmic phase. The maximum growth and oxytetracycline degradation occurred after culture for $96 \mathrm{~h}$, as indicated by an $\mathrm{OD}_{600}$ of 0.606 and a decrease in concentration from $100 \mathrm{mg} / \mathrm{l}$ to $22.3 \mathrm{mg} / \mathrm{l}$. The bacterium then entered a stationary phase. Regression analysis of the increase in $\mathrm{OD}_{600}$ and the decrease in oxytetracycline concentration showed a solid linear relationship between growth and oxytetracycline degradation, with an $\mathrm{R}^{2}$ value of 0.97 ( $p<0.01)$, indicating that oxytetracycline degradation was primarily dependent on growth of the isolate. Up to now, few oxytetracycline-degrading bacteria were isolated [10]. According to $\mathrm{Li}$ et al., compost composed of a mixture of soil and swine manure required 30 to $41 \mathrm{~d}$ for $50 \%$ oxytetracycline degradation, while 100 to $137 \mathrm{~d}$ were required for $90 \%$ degradation [8]. Thus, the new isolated bacterium has a great potential on swine manure composting to accelerate oxytetracycline degradation.

The character of bacterial growth and oxytetracycline of strain TJ-1 has been shown in Figure 3 and 4. As shown in Figure 3, strain TJ-1 could grow at pH 5-9, with an optimal $\mathrm{pH}$ of 7.0. Under the optimal $\mathrm{pH}$, the strain could also rapidly degrade oxytetracycline, as indicated by a decrease from $100 \mathrm{mg} / \mathrm{l}$ to $21.8 \mathrm{mg} / \mathrm{l}$. This optimum $\mathrm{pH}$ range ( $\mathrm{pH} 5-9)$ is broader than that of Actinomucor elegans 


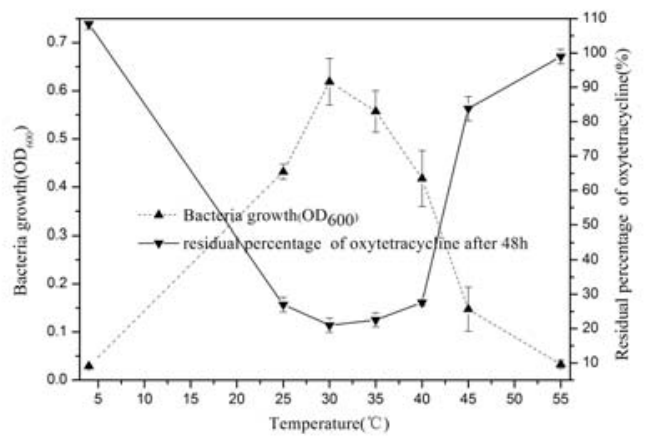

Figure 4. Effect of temperature on cell growth and oxytetracycline degradation.

TABLE III. THE RESUltS OF THE CUSTOM DESIGN.

\begin{tabular}{|c|c|c|c|c|c|}
\hline Operation & $\begin{array}{c}\text { Moisture } \\
(\%)\end{array}$ & $\mathrm{C} / \mathrm{N}$ & $\begin{array}{c}\text { Microbial } \\
\text { Inoculation } \\
(\%)\end{array}$ & $\begin{array}{c}\text { Stack- } \\
\text { turning } \\
(\mathrm{d} / \text { times })\end{array}$ & $\begin{array}{c}\text { Degradation of } \\
\text { Oxytetracycline } \\
(\%)\end{array}$ \\
\hline 1 & 50 & 20 & 0 & 3 & 59.18 \\
\hline 2 & 50 & 30 & 1 & 2 & 79.86 \\
\hline 3 & 70 & 30 & 0.5 & 3 & 89.08 \\
\hline 4 & 50 & 25 & 0.5 & 1 & 81.81 \\
\hline 5 & 70 & 25 & 0 & 2 & 83.08 \\
\hline 6 & 60 & 20 & 0.5 & 2 & 72.25 \\
\hline 7 & 60 & 30 & 0 & 1 & 86.96 \\
\hline 8 & 70 & 20 & 1 & 1 & 87.76 \\
\hline 9 & 60 & 25 & 1 & 3 & 80.76 \\
\hline $\begin{array}{c}\text { Optimal } \\
\text { Predict }\end{array}$ & 70 & 30 & 1 & 1.5 & 98.2 \\
\hline
\end{tabular}

BFL-5, which has an optimal pH of 4.5 to 5.0 [11]. As shown in Figure 4, temperature had a great effect on the growth of strain TJ-1. Specifically, this organism could grow at $25-45^{\circ} \mathrm{C}$, with the optimal growth occurring at $30^{\circ} \mathrm{C}$; however, it could not grow at greater than $45^{\circ} \mathrm{C}$. Generally, Staphylococcus have the potential to cause disease; however, since the temperature can reach $55^{\circ} \mathrm{C}$ or higher after long periods of time during composting, the organism could not survive the process, resulting in decreased risk to the environment.

\section{Bioaugmentation of strain TJ-1 to composting of swine manure}

Definitely, oxytetracycline could be absorbed by swine manure. Thus, $150 \mathrm{mg} / \mathrm{kg}$ oxytetracycline was added into sterilized swine manure and sampled to monitor oxytetracycline concentration for $7 \mathrm{~d}$ in preliminary study. The result showed that the absorption of oxytetracycline mainly occurred at the first $12 \mathrm{~h}$ and the ratio of absorption maintained in the range of $7.67 \%$ to $12.53 \%$. The degradation rate of
TABLE IV. ANALYSIS OF VARIANCE (ANOVA) OF THE FITTED LEAST SQUARE MODEL OF OXYTETRACYCLINE DEGRADATION.

\begin{tabular}{|c|c|c|c|c|c|}
\hline Source & DF & $\begin{array}{l}\text { Sum of } \\
\text { Squares }\end{array}$ & $\begin{array}{c}\text { Mean } \\
\text { Square }\end{array}$ & $F$ Value & $p$ Value $>F$ \\
\hline $\mathrm{X}_{1}$ & 1 & 0.0254 & 0.0254 & 32.1969 & $0.0048^{* * *}$ \\
\hline $\mathrm{X}_{2}$ & 1 & 0.0225 & 0.0225 & 28.4247 & $0.0060^{* * *}$ \\
\hline $\mathrm{X}_{3}$ & 1 & 0.0061 & 0.0061 & 7.7432 & $0.0497^{*}$ \\
\hline $\mathrm{X}_{4}$ & 1 & 0.0126 & 0.0126 & 15.9628 & $0.0162^{*}$ \\
\hline Regression & 4 & 0.0666 & 0.0167 & 21.0819 & $0.0060^{* * *}$ \\
\hline Error & 4 & 0.0032 & 0.0008 & & \\
\hline Total & 8 & 0.0698 & & & \\
\hline$R^{2}=0.9547$ & & & & & \\
\hline
\end{tabular}

Oxytetracycline in different composts after $12 \mathrm{~d}$ is shown in Table III. As the environmental factors changed, the degradation rate of oxytetracycline changed from $59.18 \%$ to $89.08 \%$. Compared to the absorption detected in preliminary study, the aerobic compost of swine manure was efficient to oxytetracycline degradation.

Multiple regression analysis revealed that the following second-order polynomial equation described oxytetracycline degradation.

$\mathrm{y}=0.1640+0.6512 \mathrm{x} 1+0.0122 \mathrm{x} 2+6.3867 \mathrm{x} 3-0.0459 \times 4$

where $y$ was the predicted response of the degradation rate of oxytetracycline, $\mathrm{x} 1$ was the $\%$ moisture, $\mathrm{x} 2$ was the $\mathrm{C} / \mathrm{N}$ ratio, $\mathrm{x} 3$ was the inoculation amount and $\mathrm{x} 4$ was the stack turning frequency.

ANOVA was used to evaluate the goodness of fit of the model. The correlation coefficient $\left(\mathrm{R}^{2}\right)$ was equal to 0.9547 (Table IV), which implies that more than 95\% of the sample variation can be attributed to the variables. In addition, the model was significant in statistics $(p<0.01)$ (Table IV). Taken together, these findings demonstrate that the model-predicted values agreed well with the experimental values. As shown in Table IV, all four variables had a significant effect on the degradation of oxytetracycline by strain $\mathrm{TJ}-1$, which suggests that they should be carefully controlled when designing compost systems to improve the degradation of oxytetracycline. Finally, based on the regression equation, at an initial moisture content of $70 \%, \mathrm{C} / \mathrm{N}$ ratio of 30 , inoculation amount of $1 \%$ and stack-turning of $1.5 \mathrm{~d}$, the degradation of oxytetracycline would be $98.2 \%$. Overall, these findings indicate that inoculating Staphylococcus sp. TJ-1 into manure compost is an effective method of reducing the release of oxytetracycline into the environment.

\section{CONCLUSIONS}

An Oxytetracycline-degrading bacterium (denoted TJ1) capable of using oxytetracycline as the sole source of carbon was isolated and investigated. The 16S rDNA sequence showed that it belonged was a Staphylococcus sp. with an oxytetracycline degradation rate of $77.7 \%$ at $96 \mathrm{~h}$ when cultured at $\mathrm{pH} 7.0,30^{\circ} \mathrm{C}$ and $100 \mathrm{mg} / \mathrm{l}$ oxytetracycline. According to regression equation, the 
optimal conditions for bioaugmentation with strain TJ-1 in composting to degrade oxytetracycline were as follows: $70 \%$ initial moisture, initial $\mathrm{C} / \mathrm{N}$ of 30 , microbial inoculation value of $1 \%$ and stack-turning every $1.5 \mathrm{~d}$. Under the optimal conditions, the degradation of oxytetracycline was $98.2 \%$, indicating that the organism could be used for agriculture application to reduce the oxytetracycline pollution.

\section{ACKNOWLEDGMENTS}

This work was supported by the National Science Foundation of China (21107095), Natural Science Foundation of Zhejiang Province (Y5110019), Special Foundation of Young Scientists of Zhejiang Gongshang University (QZ11-7) and the Postgraduate Technology Innovation Project of Zhejiang Gongshang University (1260XJ1513150).

\section{REFERENCES}

[1] L. Zhao, Y.H. Dong, H. Wang, Residues of veterinary antibiotics in manures from feedlot livestock in eight provinces of China. Science of the Total Environment, 408, pp. 1069-1075, 2010.

[2] Q.X. Yang, J. Zhang, K.F. Zhu, N. Yu, Influence of oxytetracycline on the structure and activity of microbial community in wheat rhizosphere soil. Journal of Environmental Sciences, 21(7), pp. 954-959, 2009.

[3] O.A. Arikan, L.J. Sikora, W. Mulbry, S.U. Khan, G.D. Foster, Composting rapidly reduces levels of extractable oxytetracycline in manure from therapeutically treated beef calves. Bioresource Technology, 98(1), pp. 169-176, 2007.

[4] S.I. Mohring, I. Strzysch, M.R. Fernandes, Degradation and elimination of various sulfonamides during anaerobic fermentation: a promising step on the way to sustainable pharmacy? Environmental Science and Technology, 43(7), pp. 2569-2574, 2009.

[5] A.C. Kolz, T.B. Moorman, S.K. Ong, K.D. Scoggin, E.A. Douglass, Degradation and metabolite production of tyrosin in anaerobic and aerobic swine-manure lagoons. Water Environment Research, 77(1), pp. 49-56, 2005.

[6] S.Q. Zhang, F.D. Zhang, X.M. Liu, Y.J. Wang, S.W. Zou, X.S. He, Determination and analysis on main harmful composition in excrement of scale livestock and poultry feedlots. Plant Nutrition and Fertilizer Science, 11(6), pp. 822-829, 2005.

[7] M. De Liguoro, V. Cibin, F. Capolongo, B. Halling-Sorensen, C. Montesissa, Use of oxytetracycline and tylosin in intensive calf farming: evaluation of transfer to manure and soil. Chemosphere, 52(1), pp. 203-212, 2003.

[8] L.L. Li, L.D. Huang, R.S. Chung, K.H. Fok, Y.S. Zhang, Sorption and dissipation of tetracyclines in soils and compost. Pedosphere, 20(6), pp. 807-816, 2010.

[9] E.X. Song, M.Z. Wang, D.S. Shen, Isolation, identification and characterization of a novel Ralstonia sp. FD-1, capable of degrading 4-fluoroaniline. Biodegradation, 25, pp. 85-94, 2014.

[10] Z.Q. Wang, C.Q. Zhang, W.X. Wang, Screening and characterization of an oxytetracycline degrading bacterium. Chinese Veterinary Sciences, 41(5), pp. 536-540, 2011.

[11] X. Luo, T. Wang, Treatment of oxytetracycline wastewater by immobilized fungus. Journal of Hebei University of Science and Technology, 32(1), pp. 98-102, 2011. 